\section{Lessons in building community support for no-take MPAs from the Mexican Caribbean}

Building trust between fishers and managers is key for management actions, including for marine protected areas (MPAs). Governments seeking to establish trust should have strong enforcement of regulations as observing illegal fishing reduces trust. Managers themselves are more trusted if they have worked with the fishing community for a long time, frequently visit fishing communities, explain management actions simply and clearly, and provide educational and training opportunities for fishers like citizen science monitoring campaigns.

Community-based no take zones (NTZs) are a type of MPA that bans the harvest of marine species from a spatially-designated area that is co-developed and co-managed by the local community. Co-managed areas like these are thought to reduce conflict and increase compliance with regulations versus more "top-down" management approaches.

The authors of this study performed 86 semi-structured interviews with members of local fishery cooperatives in the state of Quintana Roo along Mexico's Caribbean Sea to gauge their perceptions of a set of NTZs which have been operating for the past five years. The Sian Ka'an A (SKA) fishery cooperative is based in the north-end of the Sian Ka'an Biosphere Reserve which includes a number of fully-closed areas and a catch-and-release area, while the Sian Ka'an B (SKB) cooperative is located at the south-end with a lobster fishery. These two cooperatives operate in an area surrounding 2,100 hectares of NTZs.

Further south yet lies the Banco Chinchorro Biosphere Reserve and the associated fishery cooperatives of Banco Chinchorro A (BCA) and Banco Chinchorro B (BCB). The NTZs associated with these cooperatives are much larger, encompassing over 14,000 hectares. Target species here also include the Caribbean spiny lobster, in addition to queen conch, deep-water snapper, and others.

In a testament to the bottom-up approach, $6 \%$ or less of interviewees believed that scientists or managers had the ultimate say in NTZ placement. A majority believed that increasing fishery production was a primary objective of the NTZs. (However, a significant minority believed that at least some sites were chosen to be NTZs simply because they had no value to the fishery -- indicating no catch-effort would be lessened by the management action.) A minority of fishers reported increasing their catch-effort from preNTZ levels in areas surrounding the NTZs to take advantage of spillover effects.

Statistical analysis showed that the two Sian Ka'an cooperatives were distinct in their views on trustworthiness of managers from their Banco Chinchorro counterparts. The lack of trust stemmed from the lack of enforcement over the much larger NTZs. As one interviewee stated: “The problem is that [the authorities] haven't fulfilled what they said they were going to do... What purpose does an NTZ serve without people to enforce it?" Banco Chinchorro fishers reported illegal harvesting at rates between $92-94 \%$ compared to the $19-45 \%$ reported by Sian Ka'an fishers. The lack of enforcement likely contributed to the fact that Banco Chinchorro fishers were more likely to report that the NTZs had no effect or even reduced the value of fishing compared to Sian Ka'an fishers. As one fisher in the BCA group noted, "Enforcement is terrible. What's the point if we stop fishing in these areas and the poachers keep coming?"
This is a summary of: Halfway to sustainability: Management lessons from community-based, marine no-take zones in the Mexican Caribbean

Accessible at: https://marxiv.org/cs3fz

Authors: Austin Ayer, Stuart Fulton, Jacobo Caamal-Madrigal, Alejandro Espinoza-Tenorio

Added to MarXiv: April 2018

Published: Marine Policy, 2018

Suggested Citation: Lessons in building community support for no-take MPAs from the Mexican Caribbean. OCTO (2018). DOI: 10.17605/OSF IO/28RQF

See more MarXiv summaries at https://www.marxivinfo.org/ summaries

Share your research in MarXiv and the MarXiv Team may summarize it, just like this!

Step-by-step instructions on how to share your research in MarXiv are detailed at https://www.marxivinfo.org/ submission

Across all disciplines, papers available for free with a preprint (also known as "Green OA") are cited $30 \%$ more than the world average (DOI: 10.7287/peerj. preprints.3119v1) 


\section{April 2018}

\section{MarXiv Summary}

MarXiv: The free research repository for the ocean \& marine-climate sciences

Importantly, observing illegal fishing "was loosely correlated with opposition to NTZ expansion" ( $p=0.056)$. Future studies should investigate this finding in more detail. Despite the issues with enforcement, fishers nearly unanimously back renewing the NTZs for another 5-year term.

Lack of enforcement actions degrade trust. So what builds trust in the first place? Working "with the fishing communities for a long time, making frequent visits to the fishing camps, explaining the purposes and results of NTZs in clear and simple terms, and providing educational and training opportunities to fishers (for example, scientific SCUBA diver training)." A prior study from 2011 found that only $27 \%$ of Sian Ka'an fishers knew their management partners in the NTZ, which was raised to $87 \%$ by the time of this study, indicating the benefits of investing in sustained relationship-building between managers and fishers. Furthermore the authors note, "A sustained presence in the community by scientists and managers, fisher input at all stages of the project, and environmental education initiatives were cited as factors engendering community support." Citizen science campaigns allowing fishers to take part in biological monitoring helped build support by providing this sort of educational opportunity.

The MarXiv Team Nick Wehner, Director of Open Initiatives, OCTO

Raye Evrard, Project Manager, ОСTO

Allie Brown,

Project Associate, ОСто

Sarah Carr,

Chief Knowledge Broker, ОСTO

John Davis,

President, OCTO

Correspondence

Nick Wehner

nick@octogroup.org

Financial support for MarXiv comes from the David and Lucile Packard Foundation.

The views expressed herein are those of the MarXiv Team and should not be interpreted as representing the opinions or policies of the Packard Foundation or other funders of MarXiv.

MarXiv is an ОСтO Initiative
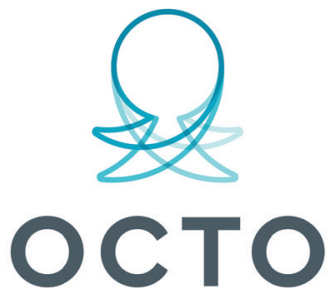

OPEN COMMUNICATIONS FOR THE OCEAN 